\title{
Protection of Whistleblowers under Czech Law within the Context of the Directive on the Protection of Persons Who Report Breaches of Union law (2019/1937)
}

\author{
Jakub Morávek ${ }^{1}$, Jan Pichrt ${ }^{2}$ \\ https://doi.org/10.18778/8220-639-5.06
}

\section{Introduction}

Since the turn of 2009, the issue of whistleblowing has been the subject of intense scrutiny in the Czech Republic. During that period, several companies involved in multinational group structures approached the Office for Personal Data Protection with regard to fulfilling their notification duty pursuant to Sec. 16 (now repealed) of Act No. 101/2000 Coll., On personal data protection. In so doing, their aim and intention was to register their internal whistleblowing systems in response to the US Federal Sarbanes-Oxley Act of 2002.

In response to these notifications, inter alia, the professional public began to deal and contend with the issue and, as a result, the first few articles on the topic were subsequently published. ${ }^{3}$ These articles were published de facto in tandem

1 Doc. JUDr. Jakub Morávek, Ph.D. The author works at the Department of Labour Law and Social Security Law within the Faculty of Law, Charles University, as a reader and secretary. $\mathrm{He}$ is also the Vice-Chairman of the Czech Society for Labour Law and Social Security Law and is a practicing attorney in Prague.

2 Prof. JUDr. Jan Pichrt, Ph.D. The author is the head of the Department of Labour Law and Social Security Law within the Faculty of Law, Charles University, and is chairman of the Czech Society for Labour Law and Social Security Law and is a practicing attorney in Prague. This chapter takes into account the situation as of 28 February 2021 and was created thanks to the support provided under the research project entitled 'Private Law and Challenges Today', ID. No. PROGRES Q03, and the UNCE project (research centre) - Dependent work in the 21st century - questions and challenges.

3 See e.g. J. Pichrt, J. Morávek, Whistleblowing, Law for Business and Employment, St. No. 7-8, 2009, pp. 19-25, J. Pichrt et al., Whistleblowing and related aspects - international conference, Wolters Kluwer, Prague 2013. 
with the first reports and materials that had been issued by the non-profit sector. ${ }^{4}$ Additionally, various professional conferences and discussion forums eventually followed. ${ }^{5}$

Relatively shortly thereafter, the topic of whistleblowing was also 'discovered' by political leaders, who sensed its political potential, especially in connection with the fight against corruption. Such a discovery was then followed by a number of unsuccessful attempts by the legislature to adopt whistleblowing legislation.

The presented chapter briefly summarizes the current legislative efforts and outlines the existing institutions of whistleblower protection under Czech law, and discusses the current form of the bill on whistleblower protection, intended to transpose Directive (EU) 2019/1937 of the European Parliament and Council of 23 October 2019 on the protection of persons who report breaches of Union law.

\section{Existing legislative proposals for whistleblowing legislation}

Presently, two independent bills for the legal protection of whistleblowers are being heard for discussion by the Chamber of Deputies of the Parliament of the Czech Republic, and through which Directive No. 2019/1937 is intended to be transposed. The first one is a bill that was submitted by MPs from the opposition Pirate Party on 22 July 2020 . Additionally, a government bill on the protection of whistleblowers and a companion amendment bill were submitted on 9 February $2021 .^{6}$

Although the bill put forth for consideration by the Pirate Party can be regarded as being more promising ${ }^{7}$ from a number of perspectives, further attention will be paid in detail to the government bill only. However, there is no reason (unfortunately) to believe that the opposition piece would gain any political support.

Nevertheless, the current political climate, especially the pandemic situation, as well as the minority government and the upcoming autumn elections for the Chamber of Deputies of the Parliament of the Czech Republic, are all extenuating circumstances which may potentially derail the success of the government bill.

4 See e.g. Whistleblowing and whistleblower protection in the Czech Republic. Transparency International. Prague 2009.

5 Whistleblowing and related aspects - international conference, Faculty of Law, Charles University, Prague, 2013, Challenge for the Czech Republic: Whistleblowing as a protection of the financial interests of EU citizens, organized by the non-profit organization Oživení, Prague 2015.

6 See Parliament of the Czech Republic, Chamber of Deputies, 8th term. Print No. 1150/0 and No. $1151 / 0$.

7 The bill more clearly reflects the existing body of case-law of the ECtHR on the protection of whistleblowers, which is in line with the principles of a liberal democratic rule of law, and limits the scope of negotiations that may be the subject of notifications, etc. 
As such, it cannot be ruled out that even this effort will go down in history as another unsuccessful attempt to regulate whistleblowing, which would already be the seventh failure in a row to do so. Should this be case, then the Czech Republic would not be able to meet the deadline for transposition. ${ }^{8}$

For a more comprehensive overview, we briefly refer below to earlier attempts to adopt legislation on whistleblower protection.

\section{Government Bill (2012)}

In November 2012, the Government of the Czech Republic approved the first draft legislation for whistleblower protection, wherein the aim was to fulfil the government's programme statement, calling for fight against corruption.

However, the proposed legislation was fragmentary as it only dealt with notifying the law enforcement authorities and failed to consistently address the protection of whistleblowers or the disclosed party, nor did it contain any internal regulation, and furthermore whistleblowers were granted protection very 'simply', merely by virtue of incorporating the proposed piece into an existing regulation, i.e. the Anti-Discrimination Act.

The bill was subjected to considerable criticism and scrutiny from the professional public. In 2013, the government suffered a crisis and no further attention was paid to the bill, i.e. it was 'dead in the water', so to speak.

\section{Senate Bill (2013)}

In 2013, a second legislative attempt was initiated by a group of senators. Intriguing, inter alia, was the fact that the submitters were led by Libor Michálek, who, prior to winning a seat in the Senate, had become a media-famous whistleblower after being fired from his position as a result of exposing high-level corruption.

The bill that was submitted by the senators followed the path of a separate law. However, it was intended to apply only to certain employees (especially in the public sector) and only to some acts (very specifically defined, e.g., the amount of anticipated harm and/or damage, etc.). Furthermore, the bill was insufficiently elaborated in terms of the legislation. As such, the Senate subsequently returned it to the legislators to be worked through. However, there was never any further discussion about it.

8 That would be nothing new. For example, the adaptation legislation (Act No. 110/2019 Coll. and Act No. 111/2019 Coll., respectively) for the GDPR, which entered into force on 25 May 2018, was not adopted until 24 April 2019. For almost a year, it was therefore not possible to apply the general regulation adequately and to control and penalize any violations thereof. 


\section{Parliamentary Bill (2016)}

In 2016, a bill on the protection of whistleblowers was submitted by Andrej Babiš, the current Prime Minister and then Minister of Finance and Member of Parliament. It was an attempt at introducing a comprehensive statutory regulation that was significantly inspired by the then effective Slovak law on the protection of whistleblowers.

According to the bill, a wide range of persons were intended to have the right to make disclosures concerning exhaustively defined criminal offences and misdemeanours. Moreover, the bill required the prior consent of the Labour Office of the Czech Republic to engage in legal proceedings (within the framework of employment relations) against a person who was to have the status of a protected whistleblower.

Needless to say, the bill did not even manage to pass its introductory reading in the legislature. Rather, the end of the debate coincided together with the end of the term of office of the Chamber of Deputies. The reasons for this fate were many. Casting the factual reservations aside, it was primarily a matter of the fact that the bill was submitted by Babiš as a parliamentary bill without any governmental and, by extension, political support. In fact, it essentially served as a medium for a political struggle insofar as the intention to present the law was in fact announced at the same time as the bill within the meaning of the following point.

\section{Government Bill No. 2 (2017)}

The government bill from 2017, which had already been introduced in its basic form in 2016, seems to symbolically close the circle of hitherto futile attempts to regulate the protection of whistleblowers in the Czech Republic. In an effort to find a simple solution to an inherently complex problem, it very closely resembled the first government bill. This time, however, the government did not seek to expand the list of discriminatory grounds.

Whereas the fourth attempt sought to ensure the protection of whistleblowers by adding a single paragraph to Sec. 133a of Act No. 99/1963 Coll., the Code of Civil Procedure, which would extend the already existing regulation of the 'reverse' burden of proof in civil proceedings to whistleblowers as well.

Thus, for example, the burden of proof would newly be shared (transferred) even where it concerns labour law disputes between whistleblowers who would state in court that the reason for their being 'sanctioned' by the employer was due to their whistleblower activity. Ergo once again, it was a very simplistic and straightforward bill.

Similar to the Babiš bill, in this case it was in fact only a political gesture, since the bill was submitted to the Chamber of Deputies immediately before the end of the term of office, and therefore had no hope of moving to the next stage of negotiations in the legislative process. 
At the moment, Government Regulation No. 145/2015 Coll., On measures related to the reporting of suspected misconduct whilst in the service of an office, can be considered as the only partial forthright legislation vis-à-vis the protection of whistleblowers (with both eyes shut). The Regulation was issued in order to implement Act No. 234/2014 Coll., On the civil service. However, the Regulation only applies to civil servants and contains only an organizational procedure for investigating disclosures, whereas no measures with respect to protecting whistleblowers are contained therein. Moreover, its constitutional conformity is problematic since, save for the provisions of the Civil Service Act, which states that a government decree is to be adopted, the Civil Service Act does not in fact provide anything more detailed about its content. The legal authority to issue an implementing regulation for the content in question is therefore not sufficient.

And so, the question thus arises: What is the cause for the repeated failures in formulating the statutory legislation of whistleblower protection in the Czech Republic?

If we were to leave out the political stage, the failures experienced to date are likely due to the necessary cross-section of the future legislation on whistleblower protection, along with the endemic complexity of regulations on individual areas upon which it should fall (e.g., employment relationships, service-supply relationships, etc.), their varying natures (i.e. employment relationships are public, whereas labour and service-supply relationships are of a private nature), and the fact that the vast majority of them have their own institutes as well as mandatory rules for preventing unjustified interference with the rights of persons who are in a weaker position.

For example, an employment relationship may be terminated unilaterally by the employer by way of giving notice or upon immediate termination, however, only if a statutory causal reason can be demonstrated and fulfilled, while the same applies to transferring to another job. Moreover, there must also be a legitimate reason for reducing an employee's remuneration, etc. With regard to the system of court proceedings, as a rule, the duty and burden of proof lie primarily with the employer, even in a dispute that has been initiated by an employee. The aforementioned similarly applies to service-supply relationships.

At the same time, legislation is in place on the protection of personal data, providing consistent protection for both whistleblowers and disclosed parties alike.

One must bear in mind that anti-discrimination legislation and the associated possibilities of private and public sanctions cannot be neglected, either.

The legislation concerning the criminal liability of legal entities as well as misdemeanour legislation, or more specifically the formulation of the grounds required to be released from liability for committing misdemeanours and crimes, also have an indispensable significance. Simply put, a person must prove that they have done all that was fair and just to be required of them in order to prevent the breach of their legal obligation from occurring. This construct is conducive to many opting to create internal notification systems, adopt compliance programmes, etc. 
Although no special law exists at this time, a relatively wide-array of possibilities for the protection of whistleblowers can thus be inferred from the legal system as a whole. ${ }^{9}$ Under these circumstances, it is difficult to formulate further rules and institutes for the protection of whistleblowers.

The reason behind the insufficiency and inadequacy of whistleblower protection seems to lie elsewhere: it is cumbersome, too slow, complicated and costly to enforce the law, especially through the courts. However, ensuring the explicit legal protection of whistleblowers will hardly solve this broad issue.

\section{Bill on the Protection of Whistleblowers ${ }^{10}$}

Directive 2019/1937 provides a clear framework for transposing the legislation. Reflecting on this fact, only selected aspects of the proposed legislation will thus be mentioned, wherein there is a deviation from the basic task ensuing from the Directive. At the same time, one must bear in mind that the proposed legislation can be supplemented or amended in any way whatsoever during its journey through Parliament.

\subsection{Definition of scope - disclosure and the protected whistleblower}

The cornerstone of the whistleblower protection legislation is the delineation of the concept of 'protected disclosure' and, along with it, the protected whistleblower. In summary, both concepts de facto determine the scope of the legislation.

The proposed regulation significantly exceeds the ambit of the areas designated by the Directive which are to be affected by the whistleblower protection legislation.

A notification is to be understood as a disclosure which is made by a natural person containing information regarding:

- a possible violation having the elements of a criminal offence in general, not just in the areas within the meaning of Article 2 of Directive No. 2019/1937, or

- possible unlawful conduct committed in violation of the legislation of the Czech Republic or the European Union in the areas pursuant to Sec. 1 (2) of the bill, which de facto duplicates Article 2 of Directive No. 2019/1937,

9 Incentive measures in relation to whistleblowers de facto exclude the experience of local society from the times of non-freedom, whether during Communism, the Nazi occupation, or even further back in time in the Austro-Hungarian Empire.

10 See Parliament of the Czech Republic, Chamber of Deputies, 8th term. Print No. 1150/0 and No. 1151/0, https://www.psp.cz/sqw/historie.sqw?o=8\&T=1150, accessed 01/9/2021. 
where the whistleblower became cognizant of the perpetration thereof in connection with performing their work or other similar activity. ${ }^{11}$

Thus, for illustrative purposes a protected disclosure could be, e.g., the reporting of damage caused to a symbol protected by law other than the state seal of the Czech Republic (Sec. 3 of Act No. 251/2016 Coll.); burning leaves or grass on a day other than that specified by a municipal ordinance (Sec. 4 of Act No. 251/2016 Sb.); a restaurant using more than its agreed allocation of municipal land for outdoor seating purposes; dumping coal in the municipal area in front of a building without a permit ( $\$ 5$ of Act No. 251/2016 Coll.); failure to pay child support ( $\$ 196$ of Act No. 40/2009 Coll.); failure to provide the appropriate materials or time conditions to a Data Protection Officer (Sec. 62 of Act No. 110/2019 Coll.); or failure to conclude an employment contract in writing (Sec. 25 of Act No. 251/2005 Coll.). The list goes on and on in a similar fashion.

The breadth of the definition of protected disclosure thus naturally contributes to considerations of proportionality and necessity, reflections on the ideas of a liberal democratic rule of law led by personal freedom, and reasonings of an engaged civil society as a prerequisite for a functioning democratic rule of law, while at the same time the motive for one's activity is their own interest in the common good as well as a public interest that is not fuelled by any special stimuli from the public authorities purposefully directing attention in a certain persuasion and direction. In this vein, it begs the question: What is the condition of the society or the state, as well as the entire Euro-Atlantic civilization as such if, in addition to the notification duty to report any suspicion of criminal activity, as follows from the factual nature of failure to report a crime ( $\$ 368$ of Act No. 40/2009 Sb., the Criminal Code), ${ }^{12}$ and the basic preventive measures that are put in place to avert and prevent harm or injury and which are generally deemed to be sufficient mechanisms within a healthy and functioning democratic state that is governed by the rule of law, it is, however, considered (by some) necessary to create special legal figures who are responsible for regulating the reporting of all crimes and offences, and not only of these said crimes and offences, but also cases concerning other legal violations in relation to which neither the factual nature of the crime nor the offence is formulated.

The factual substance of criminal offences and misdemeanours refers to typical acts that are capable of endangering or damaging (to a significant extent) a socially recognized (sufficiently serious) interest or value. This is designated as socially harmful conduct. On the contrary, these are, in fact, the necessary prohibitions

11 The term 'work or other similar activity' is defined in the provisions of Sec. 2 para. 3 of the bill and it means: employment, service; self-employment; exercising of rights associated with participation in a legal entity; performing the function of an elected, appointed or otherwise called-upon member of a body of a legal entity; managing a trust fund; volunteering; professional experience; internship; or exercising rights and obligations under a contract for the provision of supplies, services, construction work or other similar performance, as well as for applying for a job or other similar activity.

12 Hereinafter referred to as the 'CC'. 
designed to protect the interests and values in question, which restrict, but at the same time also effectively create the starting point for a liberal democratic state that is governed by the rule of law, that is freedom. The premise of freedom and autonomy of will as the primary principle is based on the construct according to which only some tortious acts must be compulsorily reported to the public authorities (provisions of Sec. 368 of the Civil Code). What role should an institute in this construct presuppose for the reporting and disclosure of non-criminal conduct? Should the primary aim be to educate society on proper and moral behaviour? Indeed, the law has a somewhat edifying and pedagogical function in this respect. However, there must be a sufficiently decent and compelling reason for its application in that the educational function should be consistently and primarily implemented vis-à-vis undesirable socially pathological phenomena (e.g., fraud, theft, sexual abuse, etc.).

Referentially, at the level of employment relationships, an external protected disclosure of a violation which has the characteristics of neither a criminal offence nor a misdemeanour does not sufficiently affect the public interest and should pose a negligible amount of social harm (this is an anti-social insignificant act). It cannot succeed due to the lack of general interest in terms of the principle of proportionality, or, as the case may be, loyalty stemming from the principle of pacta sunt servanda. ${ }^{13}$ The same also applies to non-work-related offences and criminal offences which are not subject to the notification obligation.

Besides a sufficiently strong public interest, the case-law of the European Court of Human Rights, ${ }^{14}$ as is generally well known, imposes (which is generally accepted) several other basic conditions for protected (especially external) disclosure, which should be reflected and adhered to also in respect of the application of the proposed whistleblower protection legislation.

Nevertheless, the bill only presupposes "a reasonable belief in the veracity of the information" for a protected disclosure; it does not mention the criteria (conditions) that were derived from other jurisprudence. Moreover, there is nothing in the text of the law to indicate that external disclosure should be of a subsidiary nature; the fact that it is necessary to proceed from the conditions inferred from the case-law is mentioned by the submitter only in the explanatory memorandum.

The principle of ignorantia legis non excusat ('ignorance of the law excuses not') is one of the theoretical constructs underlying the concept of a democratic rule of law. It was never intended that the addressee would at all times have a comprehensive and complete knowledge of the legal system and, more specifically, their rights and obligations under the law. This principle is one of the manifestations of legal certainty. Its factual nature can be expressed roughly in such a way that each individual should be able to ascertain their rights and obligations. In essence, if legal certainty is to

13 Cf. the Constitutional Court of the Czech Republic in the case under file No. III. ÚS 298/12.

14 For example, Judgment of ECtHR (GC) of 12 February 2008, Guja v. Moldova, appl. No. 14227/04; Judgment of ECtHR of 21 July 2011, Heinisch v. Germany, appl. No. 28274/08. 
be adequately fulfilled, the core of the rules for a given case affecting the addressee must be intuitive, that is to say the addressee must be able to sense them.

Yet, the construction that was used by the submitter goes: "what is written in the law, must be read by the addressee together with the explanatory memorandum and the body of case-law of the EctHR (European Court of Human Rights)," which, however, seems to be disproportionately distant and looks like a far cry from the indicated construct: an expert in the field will hardly have a chance of knowing the rules.

The status of a protected whistleblower and protection against retaliation for other persons who are associated with the whistleblower (Sec. 4 of the bill) arises from the law. As such, it is not subject to any formal decision. Even in this context, only the implicit presumption of satisfying the unspoken conditions is problematic within the context of legal certainty.

Knowingly making a false disclosure should be a misdemeanour (Sec. 24), for which a possible penalty of up to CZK 50,000 may be imposed.

\subsection{Retaliatory measures}

A retaliatory measure within the meaning of Sec. 2 para. 5 of the whistleblower protection bill is understood to be an action (or omission) ${ }^{15}$ taken in connection with the whistleblower's work or other similar activity that was triggered by the whistleblower's disclosure and which may cause harm (tangible or intangible). At the same time, the bill envisages an illustrative list of retaliatory measures, e.g., termination of employment, job dismissal, discrimination, ostracism, change of working time, hampering professional development, etc. In addition to standard claims depending on the nature of the retaliation (e.g., unequal remuneration, termination of employment, etc.), the bill (Sec. 5) grants the person personally affected by retaliation the right to receive adequate compensation for any non-pecuniary damage caused.

In connection with the term or concept of retaliation, what follows from the explanatory memorandum to the bill and what is crucial from the standpoint of application practices is that within the meaning of the law retaliation will only be deemed retaliation if retaliation is the sole reason for taking such action against the whistleblower. The retaliatory measure will therefore be a measure that is triggered solely by the fact that the whistleblower made the disclosure, but not a measure also triggered by the disclosure itself. ${ }^{16}$

Here is an illustrative example. An employer undergoes an organizational change, which is the underlying reason for the termination of employment (Sec. 52 letter c) of the Labour Code). As a result of the organizational change, five out of ten employees

15 See footnote 10 for the term.

16 As in the case of the case-law presumptions of protected disclosure, from the point of view of legal certainty it would certainly be more appropriate to state expressly that the notification must be the sole cause of retaliation. 
who are in the same job position will be made redundant. The law does not regulate how the redundant employees are selected: rather, it is at the discretion of the employer to do so. Although the whistleblower may have better work performance results than other employees, he is selected as one of the five employees to be made redundant. This would not be construed as a retaliatory measure within the meaning of the Whistleblower Protection Act, insofar as the reason for the termination of employment is, first and foremost, linked to the fact that the employee's job position was cancelled and he was subsequently made redundant, this aside from the fact that he is the whistleblower.

In the provisions of Sec. 26, the whistleblower protection bill formulates a number of factual elements regarding misdemeanours. Among other things, according to the provisions of Sec. 26 para. 1 letter a) of the bill, an offence is committed by a person who does not prevent the whistleblower from being subjected to retaliation. In this context, a question arises as to the significance of the decision on the offence under the referenced provision for a civil dispute concerning a potential situation that is identified as retaliation. Pursuant to the provisions of Sec. 135 of the Civil Code, it is true that the court is bound by decisions on misdemeanours and criminal offences. In other words, will the decision on the offence actually anticipate, for example, a decision concerning the validity of the legal action or on the obligation to pay damages?

\subsection{Notification system and competent person}

As in other areas, in relation to the obligation to introduce an internal notification system, the whistleblower protection bill is somewhat stricter than Directive 2019/1937. The provisions of Sec. 8 of the bill, in response to the content of the Directive, envisage a number of persons who must implement an internal notification system. In terms of the private domain, namely Sec. 8 para. 1, letter b), which, unlike the Directive, imposes the obligation upon employers to conditionally introduce and implement an internal notification system based on having, on average, at least 25 employees $^{17}$ over the previous calendar quarter.

An entity which is obliged to introduce and implement an internal notification system is, at the same time, obliged to appoint a competent person to investigate internal disclosures and perform other tasks provided for by law, including the submission of proposals for measures to either correct or prevent an illegal situation from occurring.

Such a competent person is presumed to be of age (18+ years old), and have full autonomy and integrity within the meaning of the bill. Although the qualifications for performing this function are not explicitly stated, the tasks of the person concerned and

17 Without distinguishing the scope of employment, or the form of the basic employment relationship, i.e., whether it is an employment relationship or employees working on the basis of agreements on work performed outside the employment relationship. 
the content of the explanatory memorandum nevertheless state that such person should possess adequate legal awareness, necessary analytical and organizational skills, etc.

In the context of the above, the question again arises as to whether the proposed legislation can succeed in terms of the principle of proportionality. When considering implementation, the following must be taken into account: the costs of setting up an internal notification system, the appointment of a competent person and, on the other hand, the expected benefits and the level of protection of the public interest and legitimate interests of potentially affected persons.

At the same time, it is clear that in an insignificant number of cases of lack of public interest, the obligation to establish an internal notification system and the person concerned cannot succeed. One could typically consider seasonal work, where, for instance, a company that rents rowboats or pedal boats would employ 20 temporary workers in addition to its five regular employees for the busy season from May to October on the basis of agreements for work performed outside the employment relationship. An operator of an outdoor swimming pool or ski lift in a small mountain resort may be in the same situation. In fact, the possibilities are endless in this respect.

In these cases, the obligation clearly represents a pointless administrative burden as well as an unjustified encroachment of the liable person's proprietary domain.

Even with the possibility of sharing internal notification systems for employers with less than 250 employees, it can reasonably be assumed that the end result of the legislation would culminate in a business opportunity for internal notification service providers and competent persons other than the erroneously expected greater protection of whistleblowers.

It is indeed obvious that a small entrepreneur who, in particular, wants to properly fulfil their duties in this area and avoid liability for the offence in the sense that they have not fulfilled the obligations related to the appointment of a competent person, will find it difficult to find someone in their midst to perform such a function. Instead, the employer will have to ask around elsewhere, which would likely be cheaper in the end. However, this would still amount to an unnecessary expense.

The second option (which might be better or worse) would be to appoint an unprofessionally qualified employee as the competent person, while the fulfilment of the obligation in question would be only pro forma.

In short, one cannot get rid of the impression that essentially another 'Data Protection Officer' is being created, the only difference being that the non-fulfilment of obligations by the competent person can be qualified as a misdemeanour, carrying a possible sanction of up to CZK 100,000. In contrast, the personal data protection legislation does not recognize any offences in relation to the Data Protection Officer.

\subsection{Incentive measures}

The current whistleblower protection bill eschews the introduction of incentive measures in support of notifications, as has been the case with the most recent bill 
before that. To a large extent, this tendency can be understood as a reflection of experiences from times of non-freedom. ${ }^{18}$ On the other hand, for truly functional and effective whistleblower legislation to exist, it does not seem reasonable to completely cast aside the incentive measure and other measures of similar nature.

The reason is that, at least from the perspective of the factual level of employment relationships, the prohibition of retaliation does not represent a comprehensive solution if there is a real will to seek revenge and retribution on someone.

If the retaliatory measure consists in transfer to another job, a reduction in wages or termination of employment, etc., the defence will require a legal dispute be initiated, or a notification sent to the relevant public authority (see below), competent in dealing with the public-law aspects of the matter. Nevertheless, no decision taken by a public authority, however positive for the whistleblower, can ensure that the workplace atmosphere or interpersonal relationships would in reality be such that the whistleblower would want to remain employed by such an employer, or, as the case may be, could remain there without mental suffering or other harm.

In this context, in case the whistleblower is treated negatively (which is either highly probable or already the case), it seems appropriate to offer the whistleblower the possibility of leaving employment against a reasonable amount of severance pay. ${ }^{19}$

Another, more knowledge-intensive institution that could have an incentive effect would be the introduction of a private lawsuit in public interest, where the plaintiff would have the right to a share in protected public funds..$^{20}$

Without any instruments of a similar nature, the effectiveness of the legislation can be justifiably questioned.

\subsection{Further changes and monitoring the fulfilment of obligations}

Together with the whistleblower protection bill, a companion amendment bill was submitted to the Chamber of Deputies of the Parliament of the Czech Republic, whereby related changes are to take place, especially with regard to civil service regulations. At the same time, the bill also intends to amend the Code of Civil Procedure, which governs civil court proceedings.

18 For more on this see J. Morávek, On whistleblowing, its legitimacy and problems of international personal data transfers, [in:] J. Pichrt (ed.), Whistleblowing, Wolters Kluwer ČR, Prague 2013, pp. 187-202.

19 The choice of measures of a similar nature for non-labor relationships and other relationships of work participation seems to be much more complicated, e.g. for relationships between entrepreneurs or shareholders of legal entities.

20 For the institution and its development, see, for example, A. Kristková, The position of public action in the countries of continental Europe and in common law countries, [in:] P. Zarivnij (ed.), Public legal action and its perspectives. Acta Universitatis Brunensis. Legal, Brno: Faculty of Law, Masaryk University, 2015. No. 538. p. 6, or also see T. Gřivna, Private legal action in criminal proceedings, Karolinum, Prague 2006. 
Specifically, following the example of the second government bill from 2017, it proposes to supplement the provisions of Sec. 133a and to extend the already existing regulation of the 'reversed' burden of proof within civil court proceedings. In addition, it proposes to supplement the legislation on preliminary injunctions so that a whistleblower can request a temporary adjustment of their situation. Based on prior experience with the application of both institutions in other cases, one can conjecture that the significance of these changes will be rather limited.

The degree of effectiveness of the legislation and its enforcement in practice is largely determined by its monitoring and enforcement by the public authorities.

Originally, the whistleblower protection bill provided for the establishment of a Whistleblower Protection Agency within the Ministry of Justice. Additionally, the delegation of competences in this area to the Ombudsman and, to a large extent, the labour inspectorate, were also contemplated.

The resulting situation is such that the agenda will be entrusted to the Ministry of Justice, where, according to the explanatory memorandum to the whistleblower protection bill, ten civil servants are to be allocated to deal with such matters. However, they do not have to investigate individual cases themselves, rather they have to cooperate with labour inspection bodies in these matters, which are to be increasingly shifted to the role of 'investigators', although their previous monitoring activities have focused mainly on inspecting employment relationships and legal relationships in the field of employment. Also embarrassing is the fact that the labour inspectorate falls organizationally under another ministry, i.e. the Ministry of Labour and Social Affairs, while the experience with similar cross-competencies from the past has resulted in some vigilance.

\section{Conclusions}

In general, the objective of protecting the public interest through the protection of whistleblowers can be viewed in a positive light. In the context of the aforementioned reasons, however, it can be regarded that the transposition legislation in the Czech Republic will finally result in a rather general increase in terms of the administrative burden and financial burden on liable persons. There will be a positive effect in relation to the protection of the whistleblower whereas the fulfilment of the primary objectives of European legislation will be rather limited. The reasons are varied and plentiful, ranging from historical conditions to the structure and construction of the Czech law. The diversity of these aspects is, after all, one of the reasons why a directive rather than a regulation was chosen at the European level.

A more favourable outcome for effectuating the transposition legislation could be expected when reflecting on the local singularities, more specifically the fulfilment of the two conditions that follow from them. In the first place, it is a matter of omitting the tightening up against the basis which was laid down in the directive, in particular 
as regards the definition of the concept of protected disclosure and the content of the obligation to establish an internal notification system. In addition, the measures mentioned in point 2.4 are being introduced. These measures, which would reduce the scope of legislation and transfer more responsibility to whistleblowers, would, inter alia, better correlate with the anticipated ineptitude of public administration supervision in this area, as is currently evident from the bill.

Insofar as the bill's journey through Parliament has only just begun, one can hope for a shift in terms of content in the direction indicated. However, experience has shown that it is sheer folly to pin exaggerated hopes on legislators believing that they are capable of making any significant contributions and positive change regarding the amelioration of legislation.

\section{Abstract}

The chapter is focused on the protection of whistleblowers under Czech law within the context of the Directive on the protection of whistleblowers for persons who report breaches of Union law (2019/1937). Specifically, the chapter deals with all seven previous and current proposals for legal regulation of whistleblower protection. The authors provide a detailed discussion of the current draft of law to transpose Directive 2019/1937. The authors deal with the definition of the scope of the bill, retaliation measures, breadth of the obligation to implement a notification system, status of the responsible/concerned person in the notification system, absence of motivational measures and problematic aspects of public control.

\section{Bibliography}

Gřivna T., Private legal action in criminal proceedings, Karolinum, Prague 2006.

Kristková A., The position of public action in the countries of continental Europe and in common law countries, [in:] P. Zarivnij (ed.), Public legal action and its perspectives. Acta Universitatis Brunensis. Legal, Brno: Faculty of Law, Masaryk University, 2015.

Morávek J., On whistleblowing, its legitimacy and problems of international personal data transfers, [in:] J. Pichrt (ed.), Whistleblowing, Wolters Kluwer ČR, Prague 2013.

Pichrt J. et al., Whistleblowing and related aspects - international conference, Wolters Kluwer, Prague 2013.

Pichrt J., Morávek J., Whistleblowing, Law for Business and Employment, St. No. 7-8, 2009. Transparency International, Whistleblowing and whistleblower protection in the Czech Republic, Prague 2009. 